\title{
Regional resting state perfusion variability and delayed cerebrovascular uniform reactivity in subjects with chronic carotid artery stenosis
}

\author{
Arkadiusz Szarmach1, Mariusz Kaszubowski², Agnieszka Sabisz'1, Andrzej F. Frydrychowski, \\ Grzegorz Halena4, Maciej Piskunowicz'5, Jarosław Dzierzanowski ${ }^{6}$, Michał Studniarek ${ }^{5,7}$, Edyta \\ Szurowska ${ }^{1}$ and Pawel J. Winklewski ${ }^{1,3,8}{ }^{凶}$ \\ 12nd Department of Radiology, Medical University of Gdansk, Gdańsk, Poland; 2Department of Economic Sciences, Faculty of Management and \\ Economics, Gdansk University of Technology, Gdańsk, Poland; 3Department of Human Physiology, Medical University of Gdansk, Gdańsk, Po- \\ land; “Department of Cardiovascular Surgery, Medical University of Gdansk, Gdańsk, Poland; ${ }^{51-s t}$ Department of Radiology, Medical University \\ of Gdansk, Gdańsk, Poland; 'Department of Neurosurgery, Medical University of Gdansk, Gdańsk, Poland; 7Department of Diagnostic Imaging,

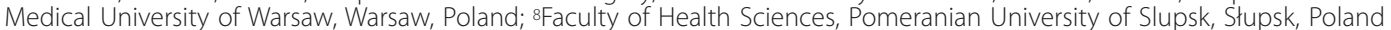

The aim of this study was to assess regional perfusion at baseline and regional cerebrovascular resistance (CVR) to delayed acetazolamide challenge in subjects with chronic carotid artery stenosis. Sixteen patients (ten males) aged $70.94 \pm 7.71$ with carotid artery stenosis $\geq 90 \%$ on the ipsilateral side and $\leq 50 \%$ on the contralateral side were enrolled into the study. In all patients, two computed tomography perfusion examinations were carried out; the first was performed before acetazolamide administration and the second 60 minutes after injection. The differences between mean values were examined by paired two-sample $t$-test and alternative nonparametric Wilcoxon's test. Normality assumption was examined using W Shapiro-Wilk test. The lowest resting-state cerebral blood flow (CBF) was observed in white matter (ipsilateral side: 18.4 \pm 6.2 ; contralateral side: $19.3 \pm 6.6$ ) and brainstem (ipsilateral side: $27.8 \pm 8.5$; contralateral side: $29.1 \pm 10.8)$. Grey matter (cerebral cortex) resting state CBF was below the normal value for subjects of this age: frontal lobe - ipsilateral side: $30.4 \pm 7.0$, contralateral side: $33.7 \pm 7.1$; parietal lobe - ipsilateral side: $36.4 \pm 11.3$, contralateral side: $42.7 \pm 9.9$; temporal lobe - ipsilateral side: $32.5 \pm 8.6$, contralateral side: $39.4 \pm 10.8$; occipital lobe ipsilateral side: $24.0 \pm 6.0$, contralateral side: $26.4 \pm 6.6$ ). The highest resting state CBF was observed in the insula (ipsilateral side: $49.2 \pm 17.4$; contralateral side: $55.3 \pm 18.4$ ). A relatively high resting state CBF was also recorded in the thalamus (ipsilateral side: $39.7 \pm 16.9$; contralateral side: $41.7 \pm 14.1$ ) and cerebellum (ipsilateral side: $41.4 \pm 12.2$; contralateral side: $38.1 \pm 11.3$ ). The highest CVR was observed in temporal lobe cortex (ipsilateral side: $+27.1 \%$; contralateral side: $+26.1 \%$ ) and cerebellum (ipsilateral side: $+27.0 \%$; contralateral side: $+34.6 \%)$. The lowest CVR was recorded in brain stem (ipsilateral side: $+20.2 \%$; contralateral side: $+22.2 \%$ ) and white matter (ipsilateral side: $+18.1 \%$; contralateral side: $+18.3 \%)$. All CBF values were provided in milliliters of blood per minute per $100 \mathrm{~g}$ of brain tissue $(\mathrm{ml} / 100 \mathrm{~g} / \mathrm{min})$. Resting state circulation in subjects with carotid artery stenosis is low in all analysed structures with the exception of insula and cerebellum. Acetazolamide challenge yields relatively uniform response in both hemispheres in the investigated population. Grey matter is more reactive to acetazolamide challenge than white matter or brainstem.
Key words: chronic carotid artery stenosis, computed tomography perfusion, acetazolamide test, cerebral blood flow, cerebral blood volume, mean transit time, time to peak

Received: 27 February, 2018; revised: 28 February, 2018; accepted: 28 February, 2018; available on-line: 12 March, 2018

e-mail: pawelwinklewski@wp.pl

Abbreviations: ASL, arterial, spin labeling; CBF, cerebral blood flow; CBV, cerebral blood volume; CCA, common carotid artery; CTP, computed tomography perfusion; CVR, cerebrovascular reactivity; DSA, digital subtraction angiography; ECA, external carotid artery; EDV, end diastolic velocity; LICA, left internal carotid artery; MTT, mean transit time; NASCET, The North American Symptomatic Carotid Endarterectomy Trial; NCCT, non, contrast computed tomography; PET, positron emission tomography; PSV, peak systolic velocity; RICA, right internal carotid artery; SPECT, single photon emission computed tomography; TTP, time to peak

Highlights

- Cerebral blood flow is low in resting state in frontal, parietal and temporal cortex grey matter in subjects with carotid artery stenosis

- A particularly low cerebral blood flow is evident in the occipital cortex

- High resting-state cerebral blood flow is observed in the insula and cerebellum

- Acetazolamide challenge yields relatively uniform response in both hemispheres in the analysed population

\section{INTRODUCTION}

Brain stroke is currently the second most common cause of death. It has been estimated that one in ten European people over 50 years of age and one in two over 70 dies for this reason (Wintermark et al., 2002). Carotid artery surgery remains one of the therapeutic options for this patient population (MRC, 1991; NASCET, 1991). However, there is accumulating evidence that vascular stiffening, rather than carotid luminal narrowing, adversely influences cognitive aging and provides a potential target for ameliorating age-related cognitive decline (Wardlaw et al., 2016). It is becoming clear that further improvement in outcomes for patients with carotid stenosis requires a better understanding of the pathophysiology of this disease (Abbot, 2016).

The population suffering from chronic carotid artery stenosis that we investigated represents an interest- 
ing pathophysiological state. It is characterized by low global cerebral blood flow (CBF), low global cerebral blood volume (CBV) and lack of significant differences at baseline regarding mean transit time (MT'T), CBF and CBV between the ipsilateral and contralateral hemisphere to stenosis (Frydrychowski et al., 2013; Szarmach et al., 2016; Szarmach et al., 2017a,b). Thus, the subjects from the described population are most likely very close to blood supply breakdown leading to stroke. Nevertheless, they still present relatively well-compensated perfusion, although at the very low end of the acceptable range. This population has already been described regarding misery perfusion and reduced cerebral metabolism. However, data related to both the regional pattern of baseline perfusion and regional cerebrovascular reactivity (CVR) in these subjects is missing.

The acetazolamide test is the procedure of choice to investigate cerebrovascular resistance (CVR) in subjects with chronic artery stenosis (Vorstrup et al., 1986; Murakami et al., 2002; Hartkamp et al., 2012). Acetazolamide is a reversible inhibitor of the enzyme carbonic anhydrase, and while the exact mechanism has yet to be unveiled, the vasodilatory effect on the brain vasculature is ascribed to carbonic acidosis (Vorstrup et al., 1984). Vasodilatory change in cerebral perfusion is usually measured 15 to 20 minutes before and after a challenge (Vorstrup et al., 1986; Hokari et al., 2008). However, the response to the acetazolamide test seems to be delayed in stenosed territories (Murakami et al., 2002; Hartkamp et al., 2012). One of our recent studies suggests that morphometric changes in the diameter of arteries originating from the circle of Willis are present even 60 minutes after the acetazolamide test (Szarmach et al., 2017a). Therefore a delayed response to vasodilatory challenge appears to provide important pathophysiological information.

Thus the aim of this study was to assess regional perfusion with the use of CTP at baseline and regional CVR in response to delayed acetazolamide challenge in subjects with chronic carotid artery stenosis. We hypothesized that in the described population there is marked heterogeneity in spatial baseline perfusion and that the delayed acetazolamide test may unveil significant differences in CVR characteristics. In particular, we expected higher CBF in cortical and deep GM and lower CBF in WM. We speculated that WM and structures fed by the vertebrobasilar circulatory system might be characterized by a relatively low CVR.

\section{MATERIAL AND METHODS}

Patients. A total of 16 symptomatic patients (ten males) aged $70.94 \pm 7.71$ fulfilling the enrolment criteria were included into the study (Table 1). This study was carried out in accordance with the recommendations of Helsinki. The experimental protocol and the study were approved by the ethics committee of Medical University of Gdansk. All volunteers gave written informed consent to participate in the study.

The following inclusion criteria were defined:

1. age $>18$ years,

2. written consent to participate in the study,

3. carotid artery stenosis $\geq 90 \%$ on the ipsilateral side and $\leq 50 \%$ on the contralateral side. The degree of internal carotid artery stenosis was assessed using Doppler ultrasonography examination and digital subtractive angiography (DSA) according to the method documented in the North American Symptomatic Carotid Endarterectomy Trial (NASCET, 1991),
4. complete circle of Willis and normal vertebral arteries (confirmed by DSA).

The following exclusion criteria were specified:

1. significant $(>70 \%)$ tandem stenosis,

2. intracranial tumours, aneurysm, vessel malformations,

3. total anterior cerebral infarct (TACI),

4. uncontrolled hyperthyroidism,

5. hypersensitivity to iodine or history of adverse effects following the administration of contrast agents,

6. stage II-V renal insufficiency were excluded from the study.

Angiography. Digital subtractive angiography was carried out before carotid artery stenting to confirm the degree of stenosis. Selective angiography of the target vessel was then performed to reveal the size of the carotid lesion, degree of stenosis, morphology of the internal carotid artery and its contribution to the circle of Willis.

Doppler ultrasound. Carotid arteries were examined with the patient in the supine position. The posterolateral transducer positions were used to examine the carotid arteries in the long and short axis. All the examinations were performed by the same operator and the same ultrasonography machine (Logiq S8, GE Healthcare) with a Doppler angle of $60^{\circ}$. On grey scale presence or absence and location of plaque were evaluated. On Doppler study peak systolic velocity (PSV) and end diastolic velocity (EDV) of common carotid artery (CCA), internal carotid artery (ICA) and external carotid artery (ECA) were evaluated. NASCET criteria were used for measuring the percentage of stenosis.

Computed tomography protocol. The imaging protocol consisted of Non-Contrast Computed Tomography (NCCT) and dynamic perfusion CT (CTP). In all subjects, CTP examinations were carried out twice: before and 60 minutes after an injection of $1.0 \mathrm{~g}$ Diamox i.v. (Mercury Pharmaceuticals, London, UK). All examinations were performed in transverse plane using a 64MDct Light Speed VCT XT scanner (GE Healthcare Technologies, Chicago, Illinois, US).

Technical procedures. All subjects underwent nonenhanced plain brain CT scans $(140 \mathrm{kV}, 335 \mathrm{mAS}, 0.9$ second rotation time, number of images $=56$, total exposure time $=6.3 \mathrm{~s}$, and CDTIvol between 50 and $60 \mathrm{mGy}$ ) to exclude intracranial haemorrhage and distinguish between acute and old ischaemic stroke.

CPT studies were conducted on $40 \mathrm{~mm}$ thick transverse axial sections. A $40 \mathrm{~mL}$ bolus of non-ionic contrast media (Optiray 350 Mallinckrodt, St. Louis, Missouri, USA) was administered into an antecubital vein using a power injector (Dual Shot Alpha 7, Nemoto Kyorindo Co., Ltd, Japan) with an injection rate of $4 \mathrm{~mL} / \mathrm{s}$. After contrast injection, a bolus of $40 \mathrm{ml}$ of physiological saline was administered. CT scanning was performed 5 seconds after the start of the injection with the following acquisition parameters: a sine mode series, $80 \mathrm{kV}, 150 \mathrm{mAs}, 5 \mathrm{~mm}$ slice thickness, $25-\mathrm{cm}$ field-of-view, rotation time $=1 / \mathrm{s}$, number of images per rotation $=8$, cine time between images $=0.5 \mathrm{~s}$, image matrix $=512 \times 512$, time interval between reconstructed images $=0.5 \mathrm{~s}$, interval $=0 \mathrm{~mm}$.

A total of 360 slices was obtained with a total scan time of 45 seconds. CDTIvol was approximately 390 $\mathrm{mGy}$ per examination. Scanning was performed at the level of the upper part of the cerebellum (over a distance of $40 \mathrm{~mm}$ ), with the gantry angle set parallel to the orbitomeatal line to avoid direct exposure of the eye lens to radiation. For the second study in each patient, 
Table 1 Subjects population.

\begin{tabular}{|c|c|c|c|c|c|}
\hline No. & Age & Gender & $\begin{array}{l}\text { Degree and site } \\
\text { of stenosis ICA }\end{array}$ & Cerebrovascular history & Concomitant diseases \\
\hline 1 & 70 & Male & $\begin{array}{l}\text { LICA restenosis } \\
>90 \%\end{array}$ & Previous left CAS, amaurosis fugax & $\begin{array}{l}\text { Coronary artery disease, previous my- } \\
\text { ocardial infarction, CABG and PTCA, } \\
\text { hypertension, renal impairment }\end{array}$ \\
\hline 2 & 69 & Male & $\begin{array}{l}\text { RICA stenosis } \\
>95 \%\end{array}$ & $\begin{array}{l}\text { Recent stroke of the right hemisphere } \\
\text { with transient contralateral hemiplegia, } \\
\text { PACl }\end{array}$ & Hypertension \\
\hline 3 & 80 & Female & $\begin{array}{l}\text { RICA restenosis } \\
>90 \%\end{array}$ & Previous RICA surgical CEA & Hypertension \\
\hline 4 & 60 & Female & LICA occlusion & $\begin{array}{l}\text { Recent stroke of the left hemisphere with } \\
\text { transient bracho-facial hemiparesis, PACI }\end{array}$ & $\begin{array}{l}\text { Hypertension, diabetes mellitus, coro- } \\
\text { nary artery disease }\end{array}$ \\
\hline 5 & 60 & Female & $\begin{array}{l}\text { RICA stenosis } \\
>90 \%\end{array}$ & $\begin{array}{l}\text { Previous stent implantation for } 99 \% \text { ste- } \\
\text { nosis in LICA }\end{array}$ & $\begin{array}{l}\text { Hypertension, coronary artery disease, } \\
\text { multiple myocardial infarctions in me- } \\
\text { dical history }\end{array}$ \\
\hline 6 & 58 & Male & $\begin{array}{l}\text { RICA restenosis } \\
>90 \%\end{array}$ & Previous RICA surgical CEA & $\begin{array}{l}\text { Hypertension, dyslipidaemia, previous } \\
\text { myocardial infarction, CABG and PTCA }\end{array}$ \\
\hline 7 & 82 & Male & $\begin{array}{l}\text { LICA stenosis } \\
>90 \%\end{array}$ & $\begin{array}{l}\text { Previous left subclavian artery revascula- } \\
\text { rization with stent implantation, } \mathrm{LACl}\end{array}$ & $\begin{array}{l}\text { Hypertension, coronary artery disease, } \\
\text { peripheral arterial disease, previous } \\
\text { PTCA }\end{array}$ \\
\hline 8 & 70 & Male & $\begin{array}{l}\text { LICA stenosis } \\
>90 \%\end{array}$ & Previous TIA, LACI & $\begin{array}{l}\text { Hypertension, diabetes mellitus, coro- } \\
\text { nary artery disease, previous myocar- } \\
\text { dial infarction, PTCA, and lower limb } \\
\text { endovascular and open revasculariza- } \\
\text { tion }\end{array}$ \\
\hline 9 & 70 & Female & $\begin{array}{l}\text { LICA occlusion in } \\
\text { intraopera-tive } \\
\text { angiogra-phy }\end{array}$ & Previous TIA, amaurosis fugax & $\begin{array}{l}\text { Hypertension, coronary artery disease, } \\
\text { previous myocardial infarction }\end{array}$ \\
\hline 10 & 71 & Male & $\begin{array}{l}\text { RICA stenosis } \\
>95 \%\end{array}$ & $\begin{array}{l}\text { Previous LICA surgical CEA with subsequ- } \\
\text { ent carotid artery stenting }\end{array}$ & $\begin{array}{l}\text { Hypertension, peripheral arterial dise- } \\
\text { ase, coronary artery disease, previous } \\
\text { myocardial infarction }\end{array}$ \\
\hline 11 & 59 & Female & $\begin{array}{l}\text { LICA steno- } \\
\text { sis }>90 \%\end{array}$ & Previous TIA, LACI & Hypertension, diabetes mellitus \\
\hline 12 & 71 & Male & $\begin{array}{l}\text { LICA stenosis } \\
>95 \%\end{array}$ & $\begin{array}{l}\text { Previous RICA surgical CEA, amaurosis } \\
\text { fugax }\end{array}$ & $\begin{array}{l}\text { Hypertension, coronary artery disease, } \\
\text { previous myocardial infarction, CABG } \\
\text { and PTCA, previous peripheral vascular } \\
\text { surgery }\end{array}$ \\
\hline 13 & 66 & Male & $\begin{array}{l}\text { LICA restenosis } \\
>95 \%\end{array}$ & $\begin{array}{l}\text { Ischaemic stroke of the left hemisphere } \\
\text { with contralateral hemiparesis and apha- } \\
\text { sia. Previous surgical LICA CEA, PACI }\end{array}$ & Hypertension \\
\hline 14 & 81 & Male & $\begin{array}{l}\text { LICA stenosis } \\
>90 \%\end{array}$ & Previous RICA surgical CEA, LACI & $\begin{array}{l}\text { Hypertension, dyslipidaemia, coronary } \\
\text { artery disease. Previous PTCA }\end{array}$ \\
\hline 15 & 68 & Male & $\begin{array}{l}\text { RICA stenosis } \\
>90 \%\end{array}$ & $\begin{array}{l}\text { Ischaemic stroke of the right hemisphere, } \\
\text { PACl }\end{array}$ & Hypertension \\
\hline 16 & 71 & Female & $\begin{array}{l}\text { LICA stenosis } \\
>90 \%\end{array}$ & $\begin{array}{l}\text { Three strokes in the past with aphasia } \\
\text { and transient right-sided plegia, PACl }\end{array}$ & $\begin{array}{l}\text { Hypertension, diabetes mellitus, atrial } \\
\text { fibrillation }\end{array}$ \\
\hline
\end{tabular}

CABG, coronary artery bypass grafting; CAS, carotid artery stenting; CEA, carotid endarterectomy; LACI, lacunar anterior cerebral infarct; LICA, left internal carotid artery; PACI, partial anterior cerebral infarct; PTCA, percutaneous transluminal coronary angioplasty; RICA, right internal carotid artery; TIA, transient ischaemic attack.

the same general slice locations and identical technical parameters were used.

The assessment of perfusion parameters was carried out from the level of the upper part of cerebellum to the middle part of cerebral hemispheres included in the examination, in the area supplied by the middle, anterior and posterior cerebral artery.

Image post-processing. Post-processing was performed by two investigators twice in each case (before and after acetazolamide administration) using a dedicated diagnostic workstation (AW 4 GE Healthcare Technologies, Wisconsin, USA) equipped with a professional post-processing software package to generate colour overlay maps of dynamic cerebral enhancement data (CT Perfusion version 4 (v 4.3.1), GE Healthcare Technologies, Wisconsin, USA). The readers were blinded to clini$\mathrm{cal}$ and radiological information.

The standardized elliptical mirrored regions of interest (ROIs) were drawn manually. Each ROI (between $1 \mathrm{~cm}^{2}$ to $4 \mathrm{~cm}^{2}$ each) was determined at all analysed levels (Figs 1, 2 and SF1) in the region of the investigated structures. The large vessels, bones and cerebrospinal fluid were automatically excluded via brain perfusion software. 


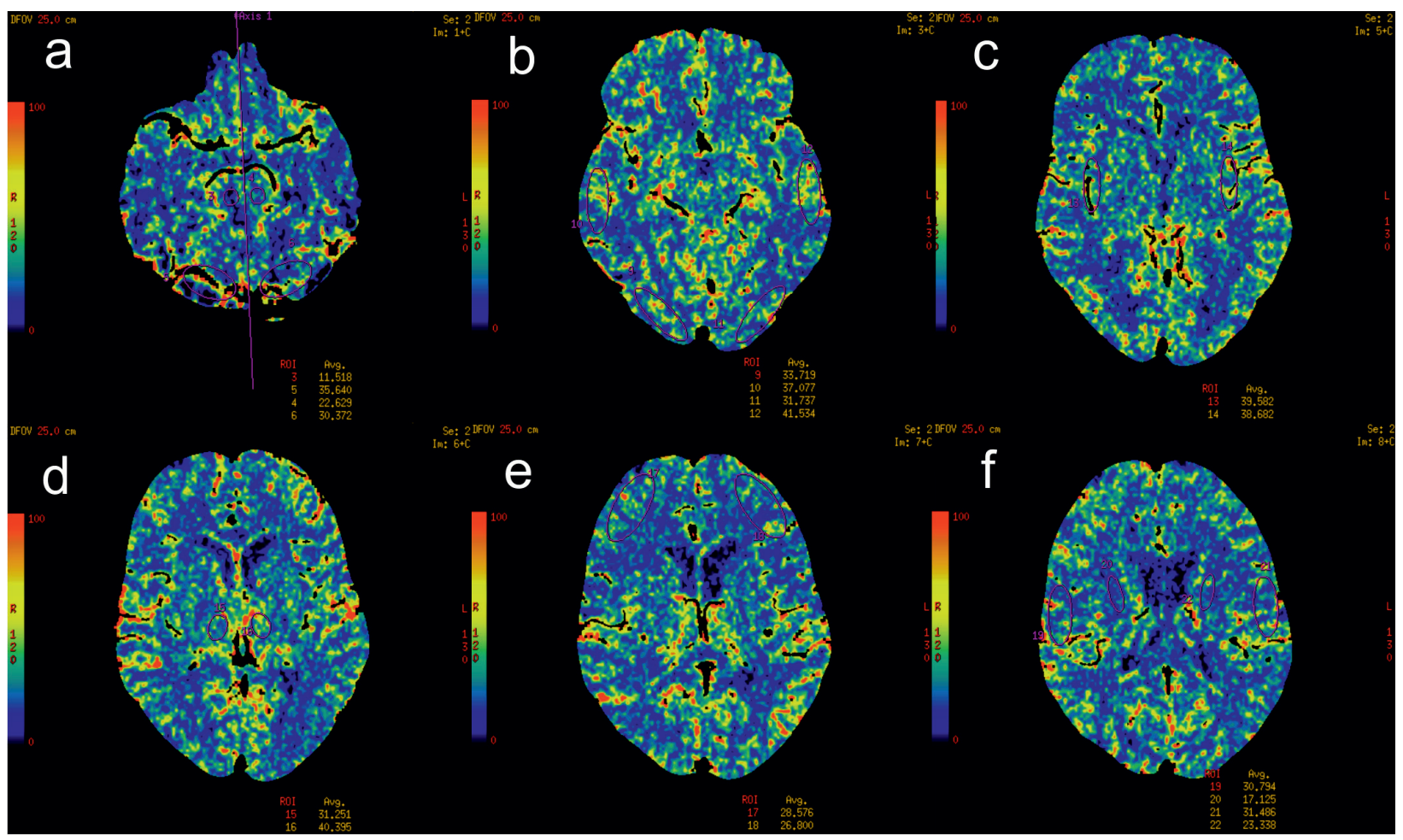

Figure 1. Pre-acetazolamide cerebral blood flow (CBF) CTP images in patient with severe right internal carotid artery (RICA) stenosis. Brainstem and cerebellum (a), occipital and temporal lobes (b), insula (c), thalamus (d), frontal lobe (e), parietal lobe and white matter of brain hemisphere $(\mathbf{f})$.

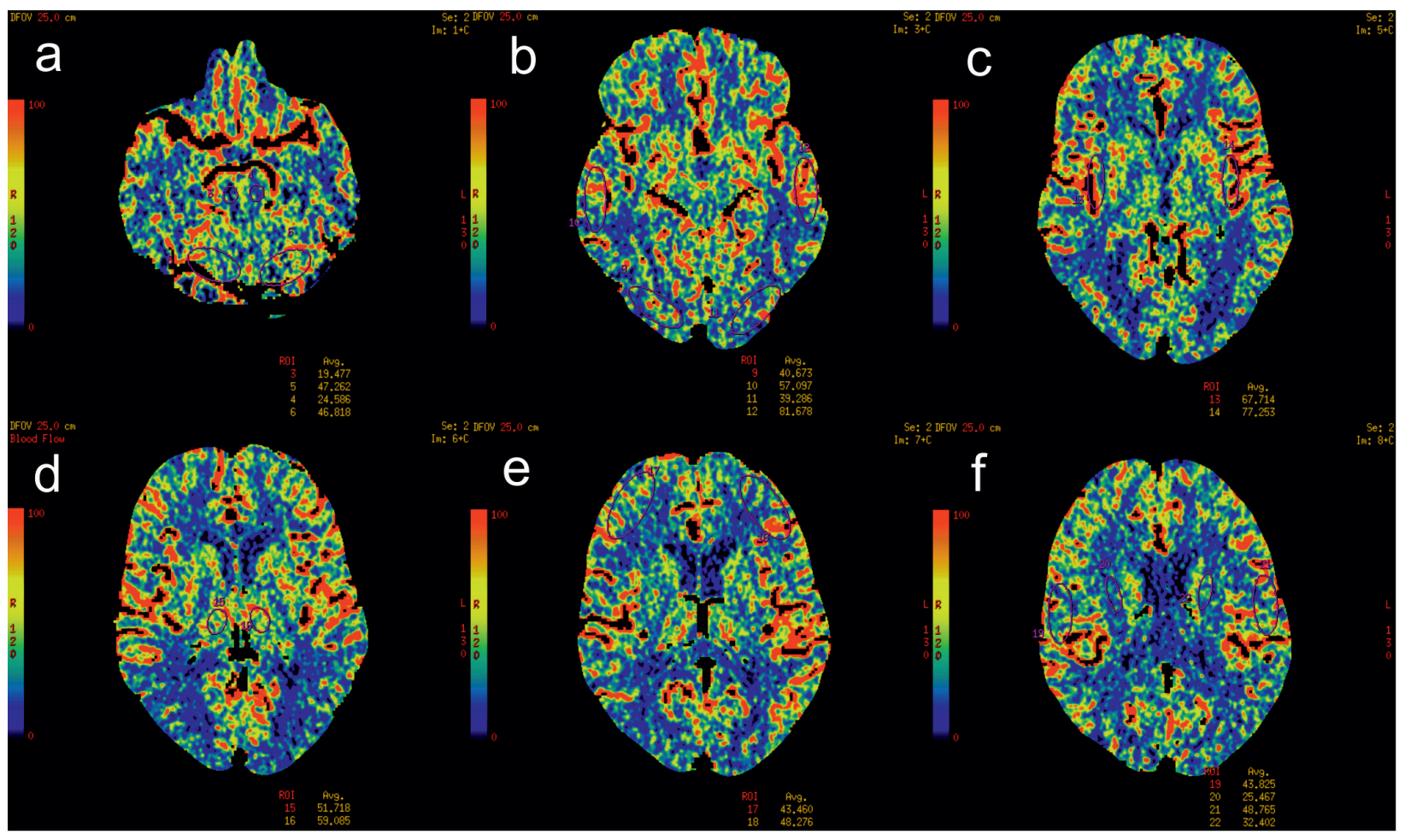

Figure 2. Post-acetazolamide cerebral blood flow (CBF) images in patient with severe right internal carotid artery (RICA) stenosis. After acetazolamide administration, there was a normal response (increase in CBF) to acetazolamide on the left side. The right hemisphere demonstrated "poorer" increase of CBF due to chronic impairment of cerebrovascular reactivity. Brainstem and cerebellum (a), occipital and temporal lobes (b), insula (c), thalamus (d), frontal lobe (e), parietal lobe and white matter of brain hemisphere (f). 
Native scans are provided as supplementary Fig. SF1 at www.actabp.pl.

The "neuro brain stroke" mode was used for calculation of the perfusion metrics of Mean Transit Time (MTT), Cerebral Blood Flow (CBF), Cerebral Blood Volume (CBV), and Time to Teak (TTP) for brain stroke assessment using the maximal slope method.

Time-enhancement curves based on the passage of contrast material through the anterior cerebral artery and the superior sagittal sinus yielded the atrial input function (AIF) and the venous output function (VOF), respectively.

The MTT corresponds to the average time that red blood cells spend within a determinate volume of capillary MT'T, computed and displayed in seconds.

The CBF is defined as the volume of blood passing through a given amount of brain tissue per unit of time, most commonly milliliters of blood per minute per $100 \mathrm{~g}$ of brain tissue $(\mathrm{ml} / 100 \mathrm{~g} / \mathrm{min})$.

The CBV is calculated as the ratio of the area under the time-concentration curve for the first contrast material bolus passage through the tissue to the area under the curve for the VOF. The blood volume is the product of the blood flow and the mean transit time: $\mathrm{CB}$ $\mathrm{V}=\mathrm{CBF}^{*} \mathrm{M}$ 'T'T.

The TTP is the time between the onset of the enhancement transient and the peak value of the time curve. Time-to-peak is computed and displayed in seconds, using the raw time curve data.

The absolute values of CT perfusion parameters (MTT, TTP, CBF, CBV) of one hemisphere in the region of anterior, middle and posterior cerebral artery distribution and contralateral mirroring areas in functional maps were measured.

Statistical analysis. To compare the results before and after acetazolamide challenge, differences in absolute CT values (MTT (s), CBV (ml/100 g), CBF (ml/100 $\mathrm{g} / \mathrm{min}$ ) and TTP (s)) and relative values (rMTT, rCBV, $\mathrm{rCBF}$ and rTTP - obtained as the ratio of appropriate values from ipsilateral side to contralateral side to stenosis) were analysed.

Raw data from all individual slices were presented as Mean \pm S.D and with Median value. Additionally, there were calculated the percentage changes of CT parameters by formula (CT2-CT1)/CT $1 \times 100 \%$ where CT1 and CT2 meant respectively CT values in the period before and after delayed acetazolamide test. Since the analysed groups were small $(\mathrm{N}=16)$ the differences between variables were examined at the same time by paired $t$-test and alternative nonparametric Wilcoxon's test. The $t$-test was stronger as it was the parametric test but in this case needed to be satisfied by the normality of paired differences. The W Shapiro-Wilk test revealed that not all of the samples fulfilled this assumption (results not presented). Therefore the best approach was to take into the consideration both tests results.

The level of significance was set at $\alpha=0.05$. All calculated $p$-values were for two-tailed tests. All raw data were analysed using the statistical software Statistica 12.5 (StatSoft, Tulsa, OK, USA).

\section{RESULTS}

Resting state CBF (ml/100 g/min), CBV (ml/100 g), MT'T (s) and TTP (s) parameters and respective delayed changes in response to acetazolamide are presented in Figs 3-10. Detailed tabular results are provided in the supplementary section of the manuscript (ST1-ST9). All responses to acetazolamide test were statistically significant. There were no statistically significant differences between hemispheres.

The lowest resting state CBF was observed in white matter (ipsilateral side: 18.4 \pm 6.2 ; contralateral side: 19.3 \pm 6.6 ) and brainstem (ipsilateral side: $27.8 \pm 8.5$; con-

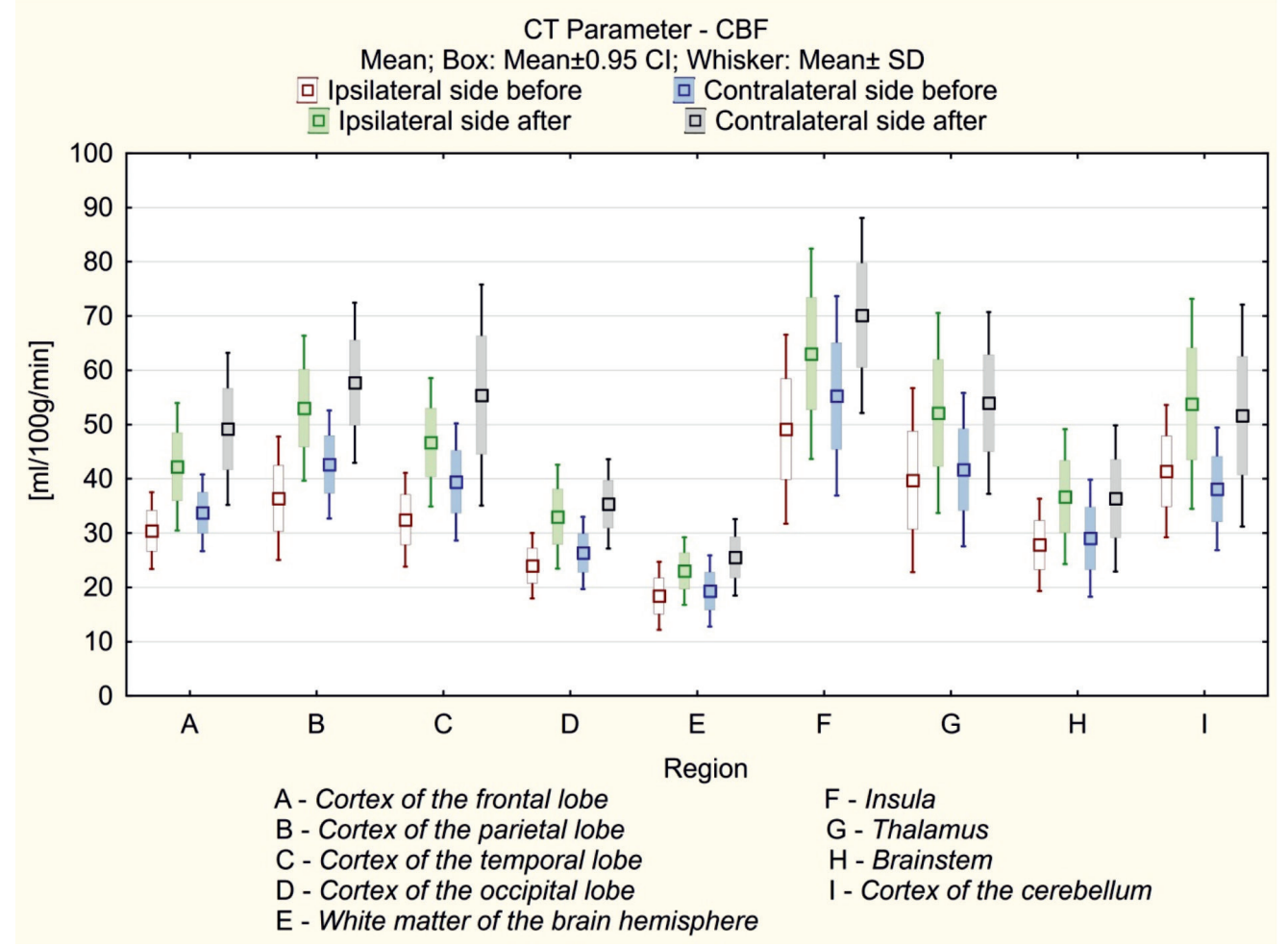

Figure 3. Resting state $\mathrm{CBF}$ and delayed $\mathrm{CBF}$ response to acetazolamide test in selected brain regions. 


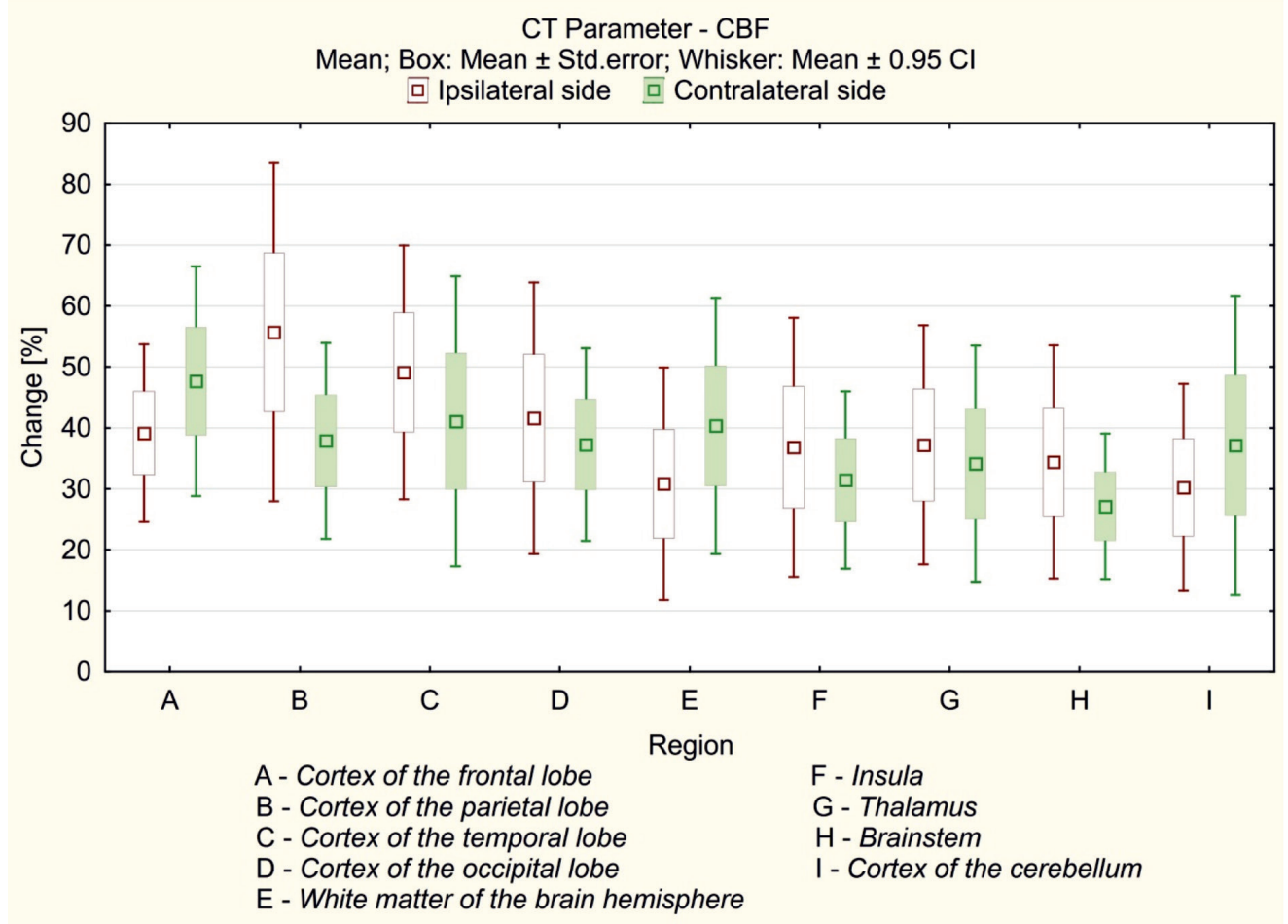

Figure 4. CBF response to delayed acetazolamide test.

tralateral side: $29.1 \pm 10.8$ ). Grey matter (cerebral cortex) resting state $\mathrm{CBF}$ was below the normal value for subjects of this age: frontal lobe - ipsilateral side: 30.4 \pm 7.0 , contralateral side: $33.7 \pm 7.1$; parietal lobe - ipsilateral

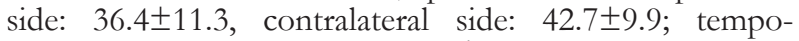
ral lobe - ipsilateral side: $32.5 \pm 8.6$, contralateral side:
39.4 \pm 10.8 ; occipital lobe - ipsilateral side: $24.0 \pm 6.0$, contralateral side: $26.4 \pm 6.6$.

The highest resting state $\mathrm{CBF}$ was observed in the insula (ipsilateral side: 49.2 \pm 17.4 ; contralateral side: $55.3 \pm 18.4)$. A relatively high resting state $\mathrm{CBF}$ was also recorded in the thalamus (ipsilateral side: $39.7 \pm 16.9$;

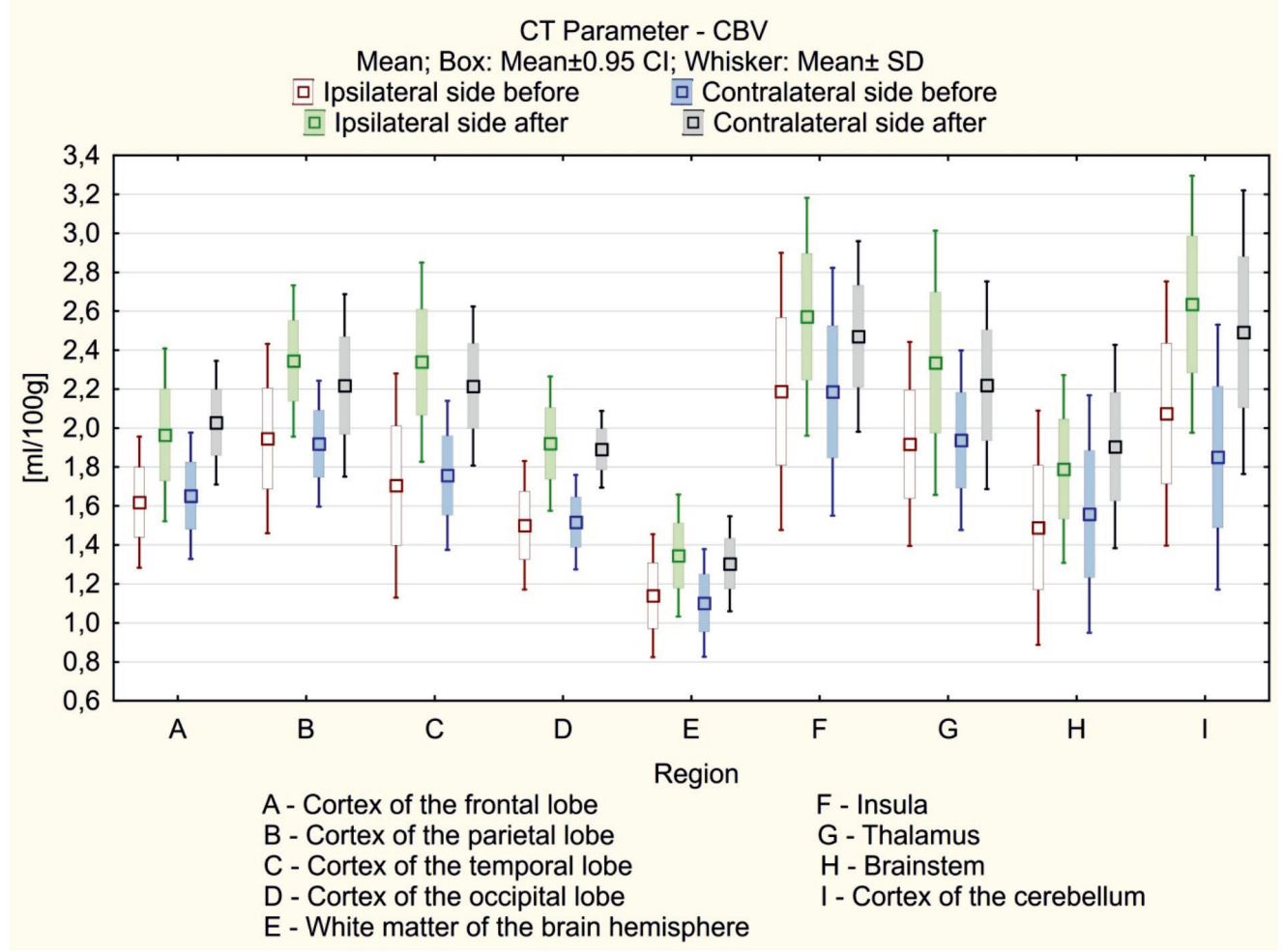

Figure 5. Resting state CBV and delayed response to acetazolamide test in selected brain regions. 


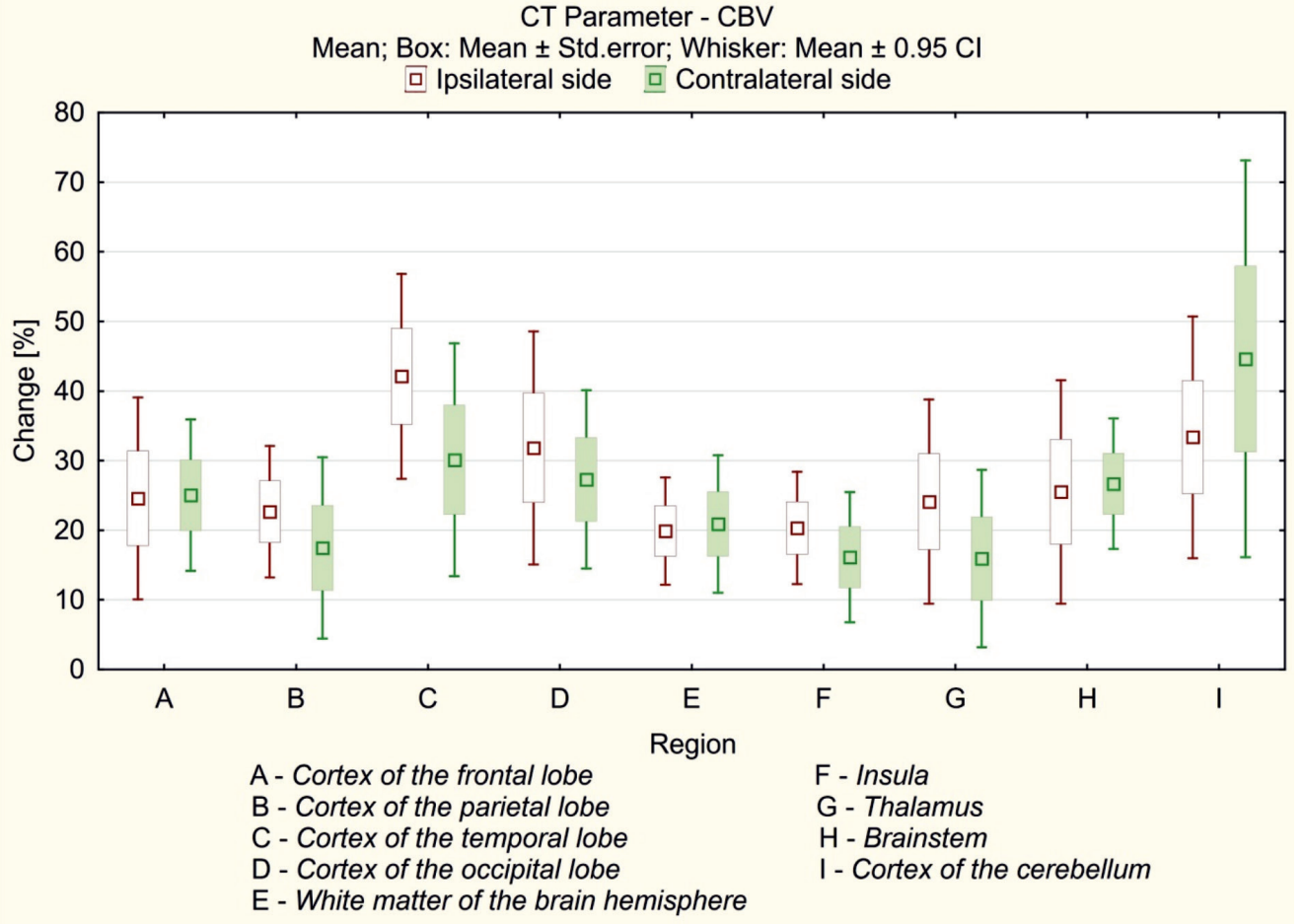

Figure 6. CBV response to delayed acetazolamide test.

contralateral side: $41.7 \pm 14.1$ ) and cerebellum (ipsilateral side: $41.4 \pm 12.2$; contralateral side: $38.1 \pm 11.3$ ).

Summing up, resting state CBF in subjects with carotid artery stenosis was low in all analysed structures with the exception of insula, thalamus and cerebellum. All values were provided in millilitres of blood per minute per $100 \mathrm{~g}$ of brain tissue $(\mathrm{ml} / 100 \mathrm{~g} / \mathrm{min})$.

The highest CVR in response to the acetazolamide test was observed in grey matter (cerebral cortex): frontal lobe - ipsilateral side: $+38.8 \%$, contralateral side:

CT Parameter - MTT

Mean; Box: Mean $\pm 0.95 \mathrm{Cl}$; Whisker: Mean \pm SD

$\begin{array}{ll}\text { ㅁ Ipsilateral side before } & \text { ㅁ Contralateral side before } \\ \text { ㅁ Ipsilateral side after } & \text { Contralateral side after }\end{array}$

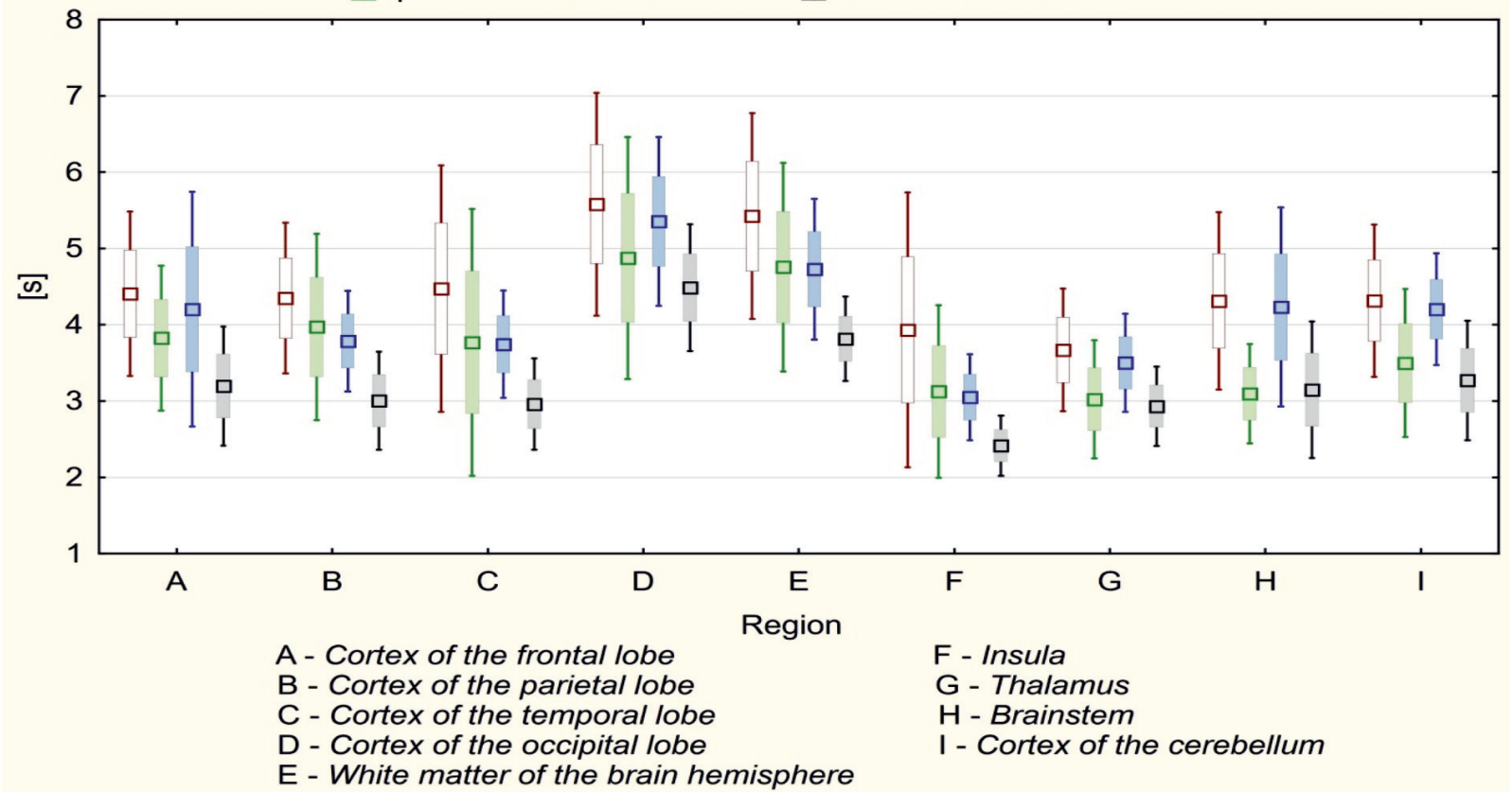

Figure 7. Resting state MTT and delayed response to acetazolamide test in selected brain regions. 
CT Parameter - MTT

Mean; Box: Mean \pm Std.error; Whisker: Mean $\pm 0.95 \mathrm{Cl}$ ㅁ Ipsilateral side $\bar{\square}$ Contralateral side

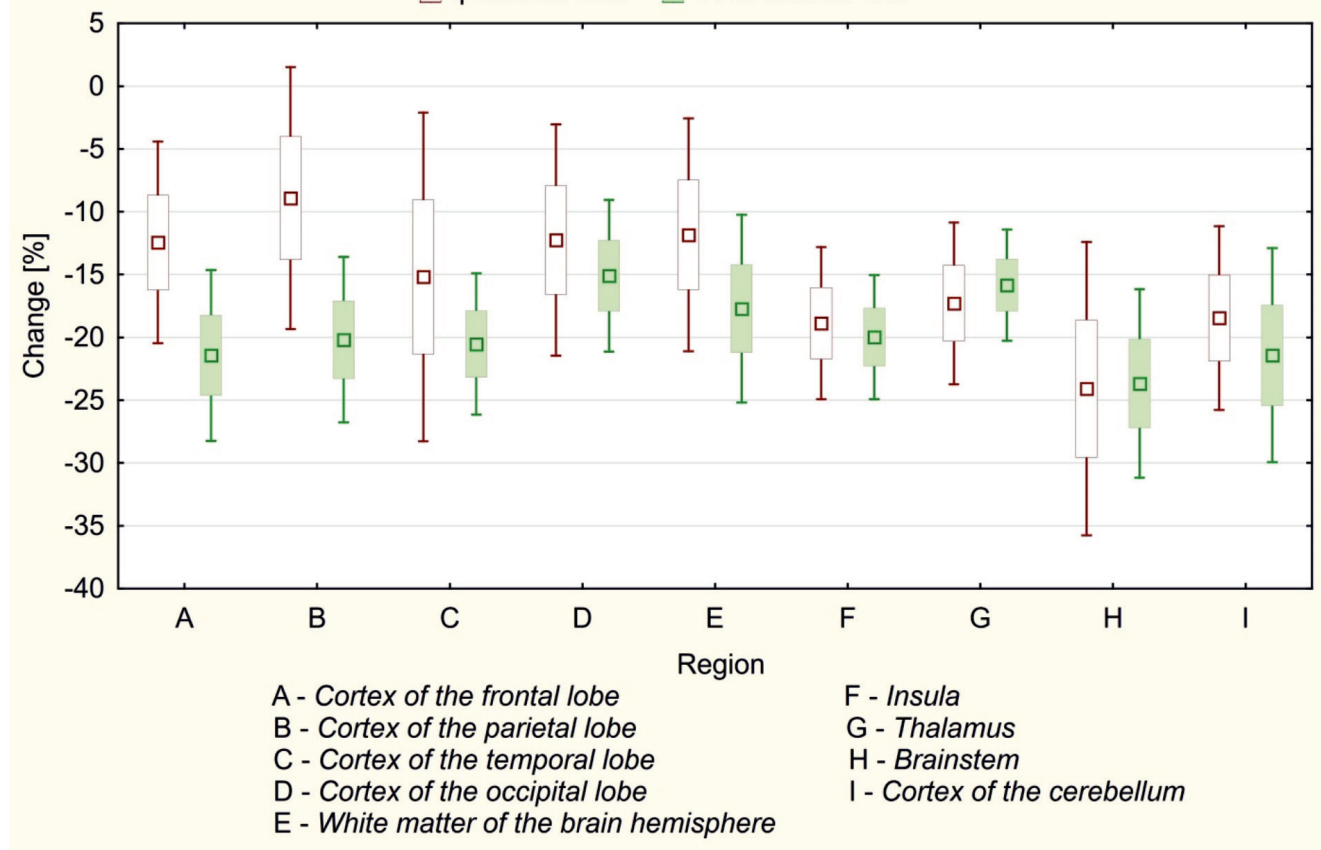

Figure 8. MTT response to delayed acetazolamide test.

$+45.9 \%$; parietal lobe - ipsilateral side: $+45.6 \%$, contralateral side: $+34.7 \%$; temporal lobe - ipsilateral side: $+43.9 \%$, contralateral side: $+40.6 \%$; occipital lobe - ipsilateral side: $+37.6 \%$, contralateral side: $+34.13 \%$. The lowest CVR was recorded in brainstem (ipsilateral side:
$+30.8 \%$, contralateral side: $+25.2 \%$ ) and white matter (ipsilateral side: $+24.8 \%$, contralateral side: $+32.1 \%$ ).

The lowest resting state CBV was observed in white matter (ipsilateral side: $1.14 \pm 0.31$; contralateral side: $1.10 \pm 0.28$ ), while in brainstem CBV was slightly higher (ipsilateral

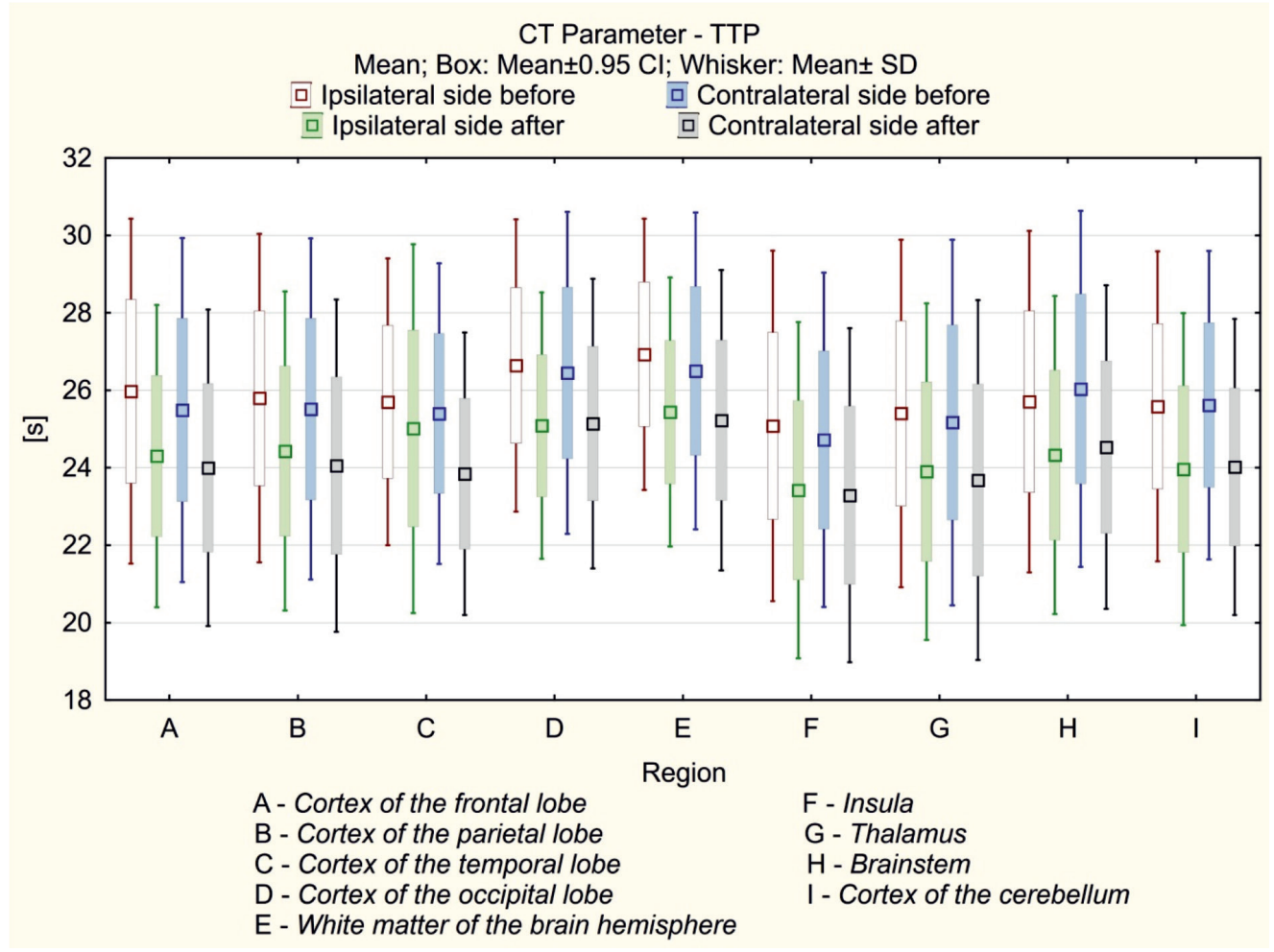

Figure 9. Resting state TTP and delayed response to acetazolamide test in selected brain regions. 


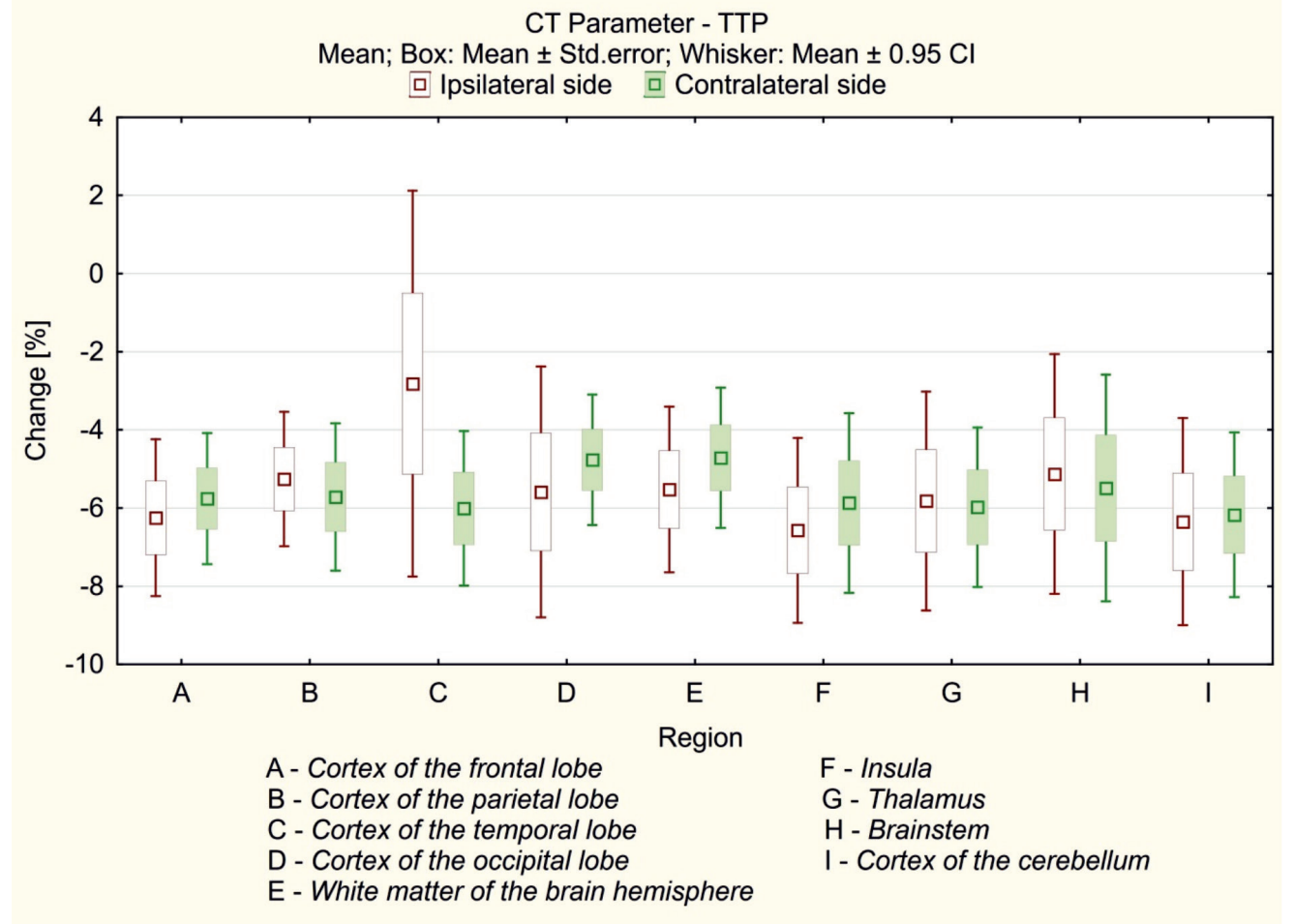

Figure 10. TTP response to delayed acetazolamide test.

side: $1.49 \pm 0.60$; contralateral side: $1.56 \pm 0.61)$ and similar to occipital cortex (ipsilateral side: $1.50 \pm 0.33$; contralateral side: $1.52 \pm 0.24)$. The highest $\mathrm{CBV}$ was recorded in insula (ipsilateral side: $2.19 \pm 0.71$; contralateral side: $2.19 \pm 0.64$ ), cerebellum (ipsilateral side: $2.08 \pm 0.68$; contralateral side: 1.85 \pm 0.68 ) and parietal cortex (ipsilateral side: 1.95 \pm 0.49 ; contralateral side: $1.92 \pm 0.32)$. All values were provided in millilitres of blood per $100 \mathrm{~g}$ of brain tissue $(\mathrm{ml} / 100 \mathrm{~g})$.

The highest CVR in response to the acetazolamide test was observed in temporal lobe cortex (ipsilateral side: $+27.1 \%$; contralateral side: $+26.1 \%$ ) and cerebellum (ipsilateral side: $+27.0 \%$; contralateral side: $+34.6 \%$ ). The lowest CVR was recorded in brainstem (ipsilateral side: $+20.2 \%$; contralateral side: $+22.2 \%$ ) and white matter (ipsilateral side: $+18.1 \%$; contralateral side: $+18.3 \%$ ).

The lowest resting state MT'T was observed in the insula (ipsilateral side: $3.93 \pm 1.80$; contralateral side: $3.05 \pm 0.57$ ) and thalamus (ipsilateral side: $3.67 \pm 0.80$; contralateral side: $3.50 \pm 0.64)$. However, MTT in the brainstem (ipsilateral side: $4.31 \pm 1.162$; contralateral side: $4.23 \pm 1.31)$ and cerebellum (ipsilateral side: 4.31 \pm 1.0 ; contralateral side: $4.21 \pm 0.73$ ) was also relatively low. The highest resting state MTT values were recorded in white matter (ipsilateral side: 5.42 \pm 1.35 ; contralateral side: $4.73 \pm 0.92$ ) and occipital cortex (ipsilateral side: 5.58 \pm 1.46 ; contralateral side: $5.35 \pm 1.01)$. All MTT values were provided in seconds (s).

The MT'T response to the acetazolamide test was relatively uniform. The highest decrease in MTT was observed in brainstem (ipsilateral side: $-28.2 \%$; contralateral side: $-25.6 \%$ ) and cerebellum (ipsilateral side: $-19.0 \%$; contralateral side: $-22.2 \%$ ).

The lowest resting state TTP was observed in the insula (ipsilateral side: $25.1 \pm 4.5$; contralateral side: $24.7 \pm 4.3$ ), the highest in white matter (ipsilateral side: 26.9 \pm 3.5 ; contralateral side: $26.5 \pm 4.09)$ and occipital cortex (ipsilateral side: $26.6 \pm 3.8$; contralateral side: $26.5 \pm 4.2)$. Nevertheless, the resting T'TP was relatively uniform across the various brain structures. All TTP values were provided in seconds (s).

T'TP responses to the acetazolamide test were similar across the various brain regions.

\section{DISCUSSION}

To the best of our knowledge, this is the first study describing regional cerebral perfusion pattern in subjects with chronic carotid artery stenosis. There are several new findings to report. Resting state CBF was low in frontal, parietal, temporal and particularly in occipital cortex grey matter in subjects with carotid artery stenosis. The CBF observed in insula and cerebellum was relatively high. The relatively uniform response to acetazolamide challenge seems to confirm well-developed collateral blood flow in subjects with chronic carotid artery stenosis. As expected grey matter was more reactive to acetazolamide challenge than white matter or brainstem.

\section{Resting state}

Our study demonstrates substantial spatial nonuniformity in all CTP parameters in the resting state, both cortically and subcortically, independent of the hemisphere (ipsi- or contra-lateral to stenosis). In this respect, our study is consistent with an earlier arterial-spin labeling (ASL) report in healthy subjects of various ages (Chen et al., 2011). However, that examination was limited to cortical and subcortical regions, which is why we also assessed white matter, brainstem, and cerebellum.

Radiation exposure is unavoidable in CTP and represents one of the main disadvantages of this imaging technique. For this reason, the inclusion of a group of healthy control subjects is ethically impossible. Nevertheless, CTP has been shown to correlate well with positron emission tomography (PET) data, the gold standard for brain per- 
fusion measurement (Kudo et al., 2003). Also, other radiological neuroimaging techniques such as ASL (Kamano et al., 2013; Zhang et al., 2014) and single photon emission computed tomography (SPECT) (Matsumoto et al., 2013) have been validated against PET. Therefore, some limited parallel comparisons can be made with caution.

The CBF in cortex grey matter (frontal, parietal and temporal) in our population was relatively low, particularly on the ipsilateral side. In Chen and coworkers (2011) ASL study in healthy subjects the mean CBF value across the entire cortical grey matter volume was 52.6 \pm 9.3 , $52.0 \pm 10.7$, and $42.7 \pm 8.8 \mathrm{ml} / 100 \mathrm{~g} / \mathrm{min}$ in the young (age $<40$ years), middle-aged ( $40 \leq$ age $\leq 60$ years) and older adult groups (age $\geq 60$ years), respectively. Similar results in healthy volunteers were obtained by Pantano and coworkers (1984) in PET study. The MTT in the frontal, parietal and temporal cortices grey matter was within the normal range (3-5 s), suggesting relatively balanced circulation and perfusion pressure (Schumann et al., 1988; Murphy et al., 2011). The moderate CBF decline in subjects with chronic carotid stenosis is in line with other reports by our team and others (Szarmach et al., 2017a; Szarmach et al., 2017b; Niesen et al., 2004; Trojanowska et al., 2006).

The very low $\mathrm{CBF}$ in the occipital cortex was quite striking. The $\mathrm{CBF}$ in the occipital cortex can be altered even in cognitively intact and nondemented subjects in the seventh decade of age (Trojanowska et al., 2006). However, the hypometabolic occipital cortex is suggested to be prognostic for the development of mild cognitive impairment (Pikkarainen et al., 2009). Ashraf and coworkers (2015) assessed glucose metabolism with PET. Although PET of tissue metabolic activity based on regional glucose uptake does not directly measure CBF, glucose metabolism and CBF are closely correlated and often show similar results (Baron et al., 1982). Also, an MT'T in occipital cortex grey matter above $5 \mathrm{~s}$ may indicate impaired circulation haemodynamics (Schumann et al., 1988; Murphy et al., 2011) in subjects with chronic carotid artery stenosis.

The role of the cerebellum in non-motor functions is increasingly recognized. Its involvement in cognitive functions is supported by the clinical finding that lesions confined to the cerebellum produce cerebellar cognitive affective syndrome (reviewed by Tedesco et al., 2011). The cerebellum contains more than half of all the neurons in the brain, and exhibits strong interconnections with the contralateral cerebral hemisphere both in feedforward and feedback directions (Tedesco et al., 2011). However, it remains to be elucidated how changes in cerebral cortex grey matter may affect the cerebellum. Due to the parallel characteristics of cerebello-cerebral connections (Van Overwalle et al., 2017) it is tempting to speculate that the high cerebellar CBF observed in our study is compensatory in nature. In particular, the MT'T in the cerebellar cortex remained low, indicating well-balanced circulation.

Changes in biochemical markers suggestive of underlying inflammation or glial activation have been demonstrated in the insula and thalamus in subjects with obstructive sleep apnoea, a disease characterized by intermittent episodes of nocturnal hypoxia. Importantly, the greatest biochemical alterations accompanied the lowest oxygen saturation (Yadav et al., 2014; Sarma et al., 2016). It is very likely that such alterations are also present in subjects with chronic carotid artery stenosis due to misery perfusion, prolonged hypoxia and oxidative stress (Szarmach et al., 2017b). Therefore the high CBF present in our patient population might be due to inflammatory changes in these structures. Alternatively, both the insula and thalamus are involved in sympathetic brain responses triggered by oxidative stress and the activated renin-angiotensin-aldos- terone system (Winklewski et al., 2015; Winklewski et al., 2016). Sympathetic activation may add functional component that further explains augmented CBF. The low MTT suggests well-balanced circulation in these structures.

The brainstem represents an evolutionarily old structure that is responsible for the maintenance and integration of vital homeostatic and life support functions (i.e., cardiovascular, respiratory, etc., Noble et al., 1984). In the extreme conditions of complete anoxia in cats, the survival time of cerebral structures appeared to be related to the CBF, with older structures surviving 25-40 s and the cerebral cortex surviving only 14-15 s (Sugar \& Gerard, 1938). Therefore, in our study, the preserved $\mathrm{CBF}$ in phylogenetically old brain regions such as the brainstem, cerebellum, thalamus, and insula may be explained by their high reactivity to persistent hypoxia that is likely present in the described subject population.

\section{Delayed acetazolamide test}

Delayed acetazolamide challenge led to a relatively uniform response on the ipsi- and contra-lateral sides to the stenosis. It is likely that all patients in the studied population had well-developed collateral flow as the duration of carotid artery stenosis exceeded 5 years (Barnett et al., 1997; Waaijer et al., 2007). The highest difference between stenotic and non-stenotic territories was visible in MT'T response in cerebral cortex grey matter. A higher cortex MTT response on the contralateral side might be due to delayed reactivity on this side, and/or wearing off of the acetazolamide effect on the ipsilateral cortex (Murakami et al., 2002; Hartkamp et al., 2012).

As expected the highest CVR was recorded in cortex grey matter, while the lowest was in the white matter and brainstem. Significant differences in $\mathrm{CO}_{2}$ reactivity between the internal carotid artery and vertebrobasilar circulation have been proposed in several physiological Doppler studies. According to physiologists lower $\mathrm{CO}_{2}$ reactivity in the vertebrobasilar system may reflect conservative and relatively stable blood flow to the medulla oblongata to maintain vital systemic functions, while high $\mathrm{CO}_{2}$ reactivity in the internal carotid artery system ensures proper tolerance to varied blood flow demand in the cerebral cortex (Sato et al., 2012; Skow et al., 2013). Our study confirms that structures fed by the vertebrobasilar system (brain stem, occipital cortex and cerebellum) have a relatively low CVR. Surprisingly, a relatively low CVR was also observed in the insula and thalamus. This suggests that the compensatory reserve of these structures has already been partially exhausted. Such a conclusion is supported by Ito and coworkers (2002), who reported that subcortical structures like the thalamus and putamen received relatively large increases in $\mathrm{CBF}$ during hypercapnia in healthy subjects.

Low $\mathrm{CO}_{2}$ reactivity in white matter is typically explained by its relatively lower degree of vascularization compared to grey matter (Mandell et al., 2008; Bhogal et al., 2014). Mandell and coworkers (2008) demonstrated a CBF "stealing effect" in white matter in response to rapid $\mathrm{CO}_{2}$ partial tension increases. Interestingly, a selective reduction in $\mathrm{CBF}$ to white matter during mild hypercapnia in young, healthy human subjects occurs precisely in those locations where elderly patients develop leukoaraiosis (Mandell et al., 2008). Our results collected one hour after acetazolamide challenge support the concept that white matter CVR is low compared to other structures. Consequently, its ability to respond to variations in $\mathrm{CO}_{2}$ supply might be deteriorated in older subjects.

Delayed acetazolamide test might be better suited for elderly subjects with several cardiovascular diseases and 
most likely diminished CVR. To the best of our knowledge our team is the first to show that the acetazolamide effect persists for at least 60 minutes in subjects with chronic carotid artery stenosis (Szarmach et al., 2017a). There is accumulating evidence that CVR should be seen as a process of temporally and spatially defined dynamics rather than a single value based on measurement at the point of the highest response (Bhogal et al., 2014; Bhogal et al., 2015; Bhogal et al., 2016). It has been demonstrated that various white (WM) and grey matter (GM) structures in healthy subjects show substantial differences in CVR to increasing concentrations of breathing carbon dioxide $\left(\mathrm{CO}_{2}\right.$, Bhogal et al., 2014). This pattern of CVR complexity in time and space is further complicated by changes observed in healthy aging (Bhogal et al., 2015; Bhogal et al., 2016; Nöth et al., 2008). Future studies in subjects with chronic carotid artery stenosis may also benefit from dynamic CVR assessment.

Computed tomography imaging and especially computed tomography perfusion (CTP) is still more commonly used than magnetic resonance imaging (MRI) because CTP has many advantages over MRI. CTP has better spatial resolution than MRI perfusion with significantly shorter study time. In this project acquisition time was less than one minute. Campbell et al. (2012) reported that quantitative computer tomography perfusion mismatch classification using two main parameters is similar to a diffusionperfusion mismatch in MRI. Imaging by MRI is very tempting because it does not use ionizing radiation. But magnetic resonance imaging has many contraindications (e.g., pacemakers, neurostimulators, cochlear implants, and claustrophobia), the study takes a long time, and patients have to remain still while scanning. Also, emergency departments are often not equipped with an MRI scanner. These key arguments favour the use of CTP.

Quantitative CTP data is highly dependent on the postprocessing software and the investigators. Software differences are frequently considered the main cause of variability in perfusion results relative to interoperator and intraoperator differences (Kudo et al., 2010; Kamalian et al., 2011). To avoid technical mistakes we used equipment manufactured by one producer and used the same post-processing procedure for all subjects, increasing the reliability of the study. Furthermore, both experienced neuroradiologists independently drew two standardized elliptical mirrored ROIs in the same patients twice (before and after acetazolamide administration; Fig 1 and 2, SF1). Finally, in all subjects, we used a coverage size of $40 \mathrm{~mm}$, which is well suited for detecting perfusion parameters owing to the high density of the scans (Szarmach et al., 2016).

The number of studied subjects involved in the study is relatively small and heterogeneous in terms of medical history, including previous history of stroke, carotid artery endarterectomy and stenting. The study population is nevertheless representative for a group of patients with chronic carotid artery stenosis (Szarmach et al., Szarmach et al., 2016; Szarmach et al., 2017a; Szarmach et al., 2017b). Moreover, the study group is very homogeneous with respect to low $\mathrm{CBV}$ and $\mathrm{CBF}$ values due to strict inclusion criteria (carotid stenosis $>90 \%$ on the ipsilateral side, less than $50 \%$ on the contralateral side, complete circle of Willis and normal vertebral arteries).

The study raises several important questions from the clinical perspective that should be answered in future research. Is the low resting state $\mathrm{CBF}$ in occipital grey cortex related to cognitive impairment in the studied population? Is the high resting state $\mathrm{CBF}$ in the cerebellum compensatory in nature? Are the observed results in the insula and thalamus compensatory or inflammato- ry in nature? Finally, how do the described changes affect functional outcome and prognosis? Future research may include combined ASL, BOLD-MRI, and dynamic contrast-enhanced (DCE)-MRI studies to address these questions. Hypoxia and inflammation are increasingly recognized as the pathophysiological background in several neurological and psychiatric diseases. Consequently, in-depth studies in larger groups of subjects suffering from prolonged hypoxia and the chronic inflammatory state may provide benefits to several fields in medicine.

\section{CONCLUSIONS}

To conclude, we have shown a relatively low resting state $\mathrm{CBF}$ in frontal, parietal and temporal cortex grey matter in subjects with carotid artery stenosis. A particularly low CBF was evident in the occipital cortex. The MTT in cortex grey matter tentatively suggests a balanced circulation. The high resting state $\mathrm{CBF}$ observed in the insula and cerebellum might be compensatory or inflammatory in nature. The relatively uniform response to acetazolamide challenge seems to confirm well-developed collateral blood flow in subjects with chronic carotid artery stenosis. Grey matter is more reactive to acetazolamide challenge than white matter or brainstem in the studied population.

\section{Author contributions}

AS and PJW conceived and designed the experiments; AS, GH and MP performed the experiments; AS, MK and PJW analysed the data; AS, GH, MK, AF, MP, JD, MS, PL, ES, PJW wrote or critically reviewed the manuscript; all authors accepted the final version of the manuscript.

\section{Conflict of interest}

\section{None.}

\section{REFERENCES}

Abbott A (2016) Critical issues that need to be addressed to improve outcomes for patients with carotid stenosis. Angiology 67: 420-426. Doi: $10.1177 / 0003319716631266$

Ashraf A, Fan Z, Brooks DJ, Edison P (2015) Cortical hypermetabolism in MCI subjects: a compensatory mechanism? Eur J Nucl Med Mol Imaging 42: 447-458. Doi: 10.1007/s00259-014-2919-z

Barnett HJ (1997) Hemodynamic cerebral ischemia. An appeal for systematic data gathering prior to a new EC/IC trial. Stroke 28: 18571860

Baron JC, Lebrun-Grandie P, Collard P, Crouzel C, Mestelan G, Bousser MG (1982) Noninvasive measurement of blood flow, oxygen consumption, and glucose utilization in the same brain regions in man by positron emission tomography: concise communication. $J$ Nucl Med 23: 391-399

Bhogal AA, Siero JC, Fisher JA, Froeling M, Luijten P, Philippens M, Hoogduin H (2014) Investigating the non-linearity of the BOLD cerebrovascular reactivity response to targeted hypo/hypercapnia at
7T. Neuroimage 98: 296-305. Doi: $10.1016 /$ j.neuroimage.2014.05.006

Bhogal AA, Philippens ME, Siero JC, Fisher JA, Petersen ET, Luijten PR, Hoogduin H (2015) Examining the regional and cerebral depth-dependent BOLD cerebrovascular reactivity response at $7 \mathrm{~T}$. Neuroimage 114: 239-248. Doi: 10.1016/j.neuroimage.2015.04.014

Bhogal AA, De Vis JB, Siero JC, Petersen ET, Luijten PR, Hendrikse J, Philippens ME, Hoogduin H (2016) The BOLD cerebrovascular reactivity response to progressive hypercapnia in young and elderly. Neuroimage 139: 94-102. Doi: 10.1016/j.neuroimage.2016.06.010

Campbell BC, Christensen S, Levi CR, Desmond PM, Donnan GA, Davis SM, Parsons MW (2012) Comparison of computed tomography perfusion and magnetic resonance imaging perfusion-diffusion mismatch in ischemic stroke. Stroke 43: 2648-2653

Chen JJ, Rosas HD, Salat DH (2011) Age-associated reductions in cerebral blood flow are independent from regional atrophy. Neuroimage 55: 468-478. Doi: 10.1016/j.neuroimage.2010.12.032

Frydrychowski AF, Winklewski PJ, Szarmach A, Halena G, Bandurski T (2013) Near-infrared transillumination back scattering sounding - 
new method to assess brain microcirculation in patients with chronic carotid artery stenosis. PLoS One 8: e61936. Doi: 10.1371/journal. pone.0061936

Hartkamp NS, Hendrikse J, van der Worp HB, de Borst GJ, Bokkers RP (2012) Time course of vascular reactivity using repeated phase-contrast MR angiography in patients with carotid artery stenosis. Stroke 43: 553-556. Doi: 10.1161/STROKEAHA.111.637314

Hokari M, Kuroda S, Shiga T, Nakayama N, Tamaki N, Iwasaki Y (2008) Combination of a mean transit time measurement with an acetazolamide test increases predictive power to identify elevated oxygen extraction fraction in occlusive carotid artery diseases. $J$ Nucl Med 49: 1922-1927. Doi: 10.2967/jnumed.108.054379

Ito H, Kanno I, Ibaraki M, Hatazawa J (2002) Effect of aging on cerebral vascular response to $\mathrm{PaCo} 2$ changes in humans as measured by positron emission tomography. J Cereb Blood Flow Metab 22: 9971003

Kamalian S, Kamalian S, Maas MB, Goldmacher GV, Payabvash S, Akbar A, Schaefer PW, Furie KL, Gonzalez RG, Lev MH (2011) CT cerebral blood flow maps optimally correlate with admission diffusion-weighted imaging in acute stroke but thresholds vary by postprocessing platform. Stroke 42: 1923-1928. Doi: 10.1161/ STROKEAHA.110.610618

Kamano H, Yoshiura T, Hiwatashi A, Abe K, Togao O, Yamashita $\mathrm{K}$, Honda H (2013) Arterial spin labeling in patients with chronic cerebral artery steno-occlusive disease: correlation with (15)O-PET. Acta Radiol 54: 99-106. Doi: 10.1258/ar.2012.120450

Kudo K, Sasaki M, Yamada K, Momoshima S, Utsunomiya H, Shirato H, Ogasawara K (2010) Differences in CT perfusion maps generated by different commercial software: quantitative analysis by using identical source data of acute stroke patients. Radiology 254: 200209. Doi: $10.1148 /$ radiol. 254082000

Kudo K, Terae S, Katoh C, Oka M, Shiga T, Tamaki N, Miyasaka K (2013) Quantitative cerebral blood flow measurement with dynamic perfusion CT using the vascular-pixel elimination method: comparison with $\mathrm{H} 2(15) \mathrm{O}$ positron emission tomography. AJNR Am J Neuroradiol 24: 419-426

Murphy MJ, Tichauer KM, Sun L, Chen X, Lee TY (2011) Mean transit time as an index of cerebral perfusion pressure in experimental systemic hypotension. Physiol Meas 32: 395-405. Doi: 10.1088/09673334/32/4/002

Mandell DM, Han JS, Poublanc J, Crawley AP, Kassner A, Fisher JA, Mikulis DJ (2008) Selective reduction of blood flow to white matter during hypercapnia corresponds with leukoaraiosis. Stroke 39: 19931998. Doi: 10.1161/STROKEAHA.107.501692

Matsumoto Y, Ogasawara K, Saito H, Terasaki K, Takahashi Y, Ogasawara Y, Kobayashi M, Yoshida K, Beppu T, Kubo Y, Fujiwara S, Tsushima E, Ogawa A (2013) Detection of misery perfusion in the cerebral hemisphere with chronic unilateral major cerebral artery steno-occlusive disease using crossed cerebellar hypoperfusion: comparison of brain SPECT and PET imaging. Eur J Nucl Med Mol Imaging 40: 1573-1581. Doi: 10.1007/s00259-013-2463-2

MRC European Carotid Surgery Trial (1991) interim results for symptomatic patients with severe $(70-99 \%)$ or with mild (0-29\%) carotid stenosis. European Carotid Surgery Trialists' Collaborative Group. Lancet 337: 1235

Murakami M, Yonehara T, Takaki A, Fujioka S, Hirano T, Ushio Y (2002) Evaluation of delayed appearance of acetazolamide effect in patients with chronic cerebrovascular ischemic disease: feasibility and usefulness of SPECT method using triple injection of ECD. $J$ Nucl Med 43: 577-583

Niesen WD, Rosenkranz M, Eckert B, Meissner M, Weiller C, Sliwka U (2004) Hemodynamic changes of the cerebral circulation after stent-protected carotid angioplasty. AJNR Am J Neuroradiol 25: 1162-1167

Noble J, Jones JG, Davis EJ (1984) Cognitive function during moderate hypoxaemia. Anaesth Intensive Care 21: 180-184

North American Symptomatic Carotid Endarterectomy Trial (NASCET) Collaborators (1991) Beneficial effect of carotid endarterectomy in symptomatic patients with high-grade carotid stenosis. New Engl J Med 325: 445-453

Nöth U, Kotajima F, Deichmann R, Turner R, Corfield DR (2008) Mapping of the cerebral vascular response to hypoxia and hypercapnia using quantitative perfusion MRI at $3 \mathrm{~T}$. NMR Biomed 21: 464-472

Pantano P, Baron JC, Lebrun-Grandié P, Duquesnoy N, Bousser MG, Comar D (1984) Regional cerebral blood flow and oxygen consumption in human aging. Stroke 15: 635-41

Pikkarainen M, Kauppinen T, Alafuzoff I (2009) Hyperphosphorylated tau in the occipital cortex in aged nondemented subjects. I Neuropathol Exp Neurol 68: 65-60. Doi: 10.1097/NEN.0b013e3181a6ee45

Sarma MK, Macey PM, Nagarajan R, Aysola R, Harper RM, Thomas MA (2016) Accelerated echo planer J-resolved spectroscopic imag- ing of putamen and thalamus in obstructive sleep Apnea. Sci Rep 6: 31747. Doi: $10.1038 /$ srep 31747

Sato K, Sadamoto T, Hirasawa A, Oue A, Subudhi AW, Miyazawa T, Ogoh S (2012) Differential blood flow responses to $\mathrm{CO}_{2}$ in human internal and external carotid and vertebral arteries. J Physiol 590: 3277-3290. Doi: 10.1113/jphysiol.2012.230425

Schumann P, Touzani O, Young AR, Morello R, Baron JC, MacKenzie ET (1998) Evaluation of the ratio of cerebral blood flow to cerebral blood volume as an index of local cerebral perfusion pressure. Brain 121: 1369-1379. Erratum in: Brain 121: 2027

Skow RJ, MacKay CM, Tymko MM, Willie CK, Smith KJ, Ainslie PN, Day TA (2013) Differential cerebrovascular $\mathrm{CO}_{2}$ reactivity in anterior and posterior cerebral circulations. Respir Physiol Neurobiol 189: 76-86. Doi: 10.1016/j.resp.2013.05.036

Szarmach A, Halena G, Kaszubowski M, Piskunowicz M, Szurowska E, Frydrychowski AF, Winklewski PJ (2016) Perfusion computed tomography: $4 \mathrm{~cm}$ versus $8 \mathrm{~cm}$ coverage size in subjects with chronic carotid artery stenosis. Br J Radiol 89: 20150949. Doi: 10.1259/ bjr.20150949

Szarmach A, Winklewski PJ, Halena G, Kaszubowski M, Dzierżanowski J, Piskunowicz M, Szurowska E, Frydrychowski AF (2017a) Morphometric evaluation of the delayed cerebral arteries response to acetazolamide test in patients with chronic carotid artery stenosis using computed tomography angiography. Folia Morphol 76: 10-14. Doi: 10.5603/FM.a2016.0034

Szarmach A, Halena G, Kaszubowski M, Piskunowicz M, Studniarek M, Lass P, Szurowska E, Winklewski PJ (2017b) Carotid artery stenting and blood-brain barrier permeability in subjects with chronic carotid artery stenosis. Int J Mol Sci 18: 1008. Doi: 10.3390/ ijms18051008

Sugar O, Gerard RW (1938) Anoxia and brain potentials. I Neurophysiol 1: $558-572$

Tedesco AM, Chiricozzi FR, Clausi S, Lupo M, Molinari M, Leggio MG (2011) The cerebellar cognitive profile. Brain 134: 3672-3686. Doi: 10.1093/brain/awr266

Trojanowska A, Drop A, Jargiello T, Wojczal J, Szczerbo-Trojanowska M (2006) Changes in cerebral hemodynamics after carotid stenting: evaluation with CT perfusion studies. J Neuroradiol 33:169-74

Yadav SK, Kumar R, Macey PM, Woo MA, Yan-Go FL, Harper RM (2014) Insular cortex metabolite changes in obstructive sleep apnea. Sleep 37: 951-958. Doi: 10.5665/sleep.3668

Van Overwalle F, Heleven E, Ma N, Mariën P (2017) Tell me twice: A multi-study analysis of the functional connectivity between the cerebrum and cerebellum after repeated trait information. Neuroimage 144: 241-252. Doi: 10.1016/j.neuroimage.2016.08.046

Vorstrup S, Henriksen L, Paulson OB (1984) Effect of acetazolamide on cerebral blood flow and cerebral metabolic rate for oxygen. J Clin Invest 74: 1634-1639

Vorstrup S, Brun B, Lassen NA (1986) Evaluation of the cerebral vasodilatory capacity by the acetazolamide test before EC-IC bypass surgery in patients with occlusion of the internal carotid artery. Stroke 17: 1291-1298

Wardlaw JM, Allerhand M, Eadie E, Thomas A, Corley J, Pattie A, Taylor A, Shenkin SD, Cox S, Gow A, Starr JM, Deary IJ (2017) Carotid disease at age 73 and cognitive change from age 70 to 76 years: A longitudinal cohort study. I Cereb Blood Flow Metab 37: 3042-3052. Doi: 10.1177/0271678X16683693

Waaijer A, van Leeuwen MS, van Osch MJ, van der Worp BH, Moll FL, Lo RT, Mali WP, Prokop M (2007) Changes in cerebral perfusion after revascularization of symptomatic carotid artery stenosis: CT measurement. Radiology 245: 541-548

Winklewski PJ, Radkowski M, Wszedybyl-Winklewska M, Demkow U (2015) Brain inflammation and hypertension: the chicken or the egg? J Neuroinflammation 12: 85. Doi: 10.1186/s12974-015-0306-8

Winklewski PJ, Radkowski M, Demkow U (2016) Neuroinflammatory mechanisms of hypertension: potential therapeutic implications. Curr Opin Nephrol Hypertens 25: 410-416. Doi: 10.1097/ MNH.0000000000000250

Wintermark M, Reichhart M, Thiran JP, Maeder P, Chalaron M, Schnyder P, Bogousslavsky J, Meuli R (2002) Prognostic accuracy of cerebral blood flow measurement by perfusion computed tomography, at the time of emergency room admission, in acute stroke patients. Ann Neurol 51: 417-432

Zhang K, Herzog H, Mauler J, Filss C, Okell TW, Kops ER, Tellmann L, Fischer T, Brocke B, Sturm W, Coenen HH, Shah NJ (2014) Comparison of cerebral blood flow acquired by simultaneous [15O] water positron emission tomography and arterial spin labeling magnetic resonance imaging. J Cereb Blood Flow Metab 34: 1373-1380. doi: $10.1038 /$ jcbfm.2014.92. 